\title{
About the conception and design of anaerobic digesters in zootehnical farms
}

\author{
Ruxandra Erbașu ${ }^{1}$, and Daniela Țăpuși ${ }^{1, *}$ \\ ${ }^{1}$ Technical University of Civil Engineering Bucharest, 122-124 Lacul Tei Bvd., Bucharest, Romania
}

\begin{abstract}
Anaerobic sludge fermentation is one of the main technological steps for treating the wastewater resulting from urban consumption in the food industry. Anaerobic fermentation ensures the sludge mineralization treatment and the fermentation gas (biogas) resulting from the process can be used for the production of thermal or electric energy. The fermentation process can take place in closed reinforced concrete tanks (digesters) having different structural forms: cylinder, tapering, ovoid depending on the type of fermentation: mesophilic or thermophilic and on the performance of sludge mixing and homogenization equipment. Fermentation tanks with a capacity of 1000-4000 m3 were designed in Romania so far, the most important being those of Bucharest wastewater treatment plant made of prestressed reinforced concrete having an ovoid shape. The present paper aims at presenting the issues related to designing the fermentation tanks of the water waste plants from urban consumption in the food industry and zoo-technical farms in a new concept in which the main fermentation tank is coupled with the fermenter for the fermentation gas storage. Consequently, hereinafter structural and functional requirements for this kind of structures are presented, together with design principles and methods that must be applied in order to fulfil the performance exigencies related to strength, stability, tightness and durability.
\end{abstract}

\section{Functional and structural requirements}

The efficiency of the anaerobic fermentation process of sludge depends mainly on the following factors:

- content of organic substance in waste water;

- sludge temperature: 350-400 in the case of mesophilic fermentation and 500 in case of thermophilic fermentation;

- mixing and homogenization degree of sludge needed to provide bacteria in mass nourishment and constant temperature throughout the sludge mass.

Taking into account these factors, it is necessary that the tanks will be equipped with performing mixing and homogenization devices able to prevent gravitational and thermal stratification of sludge. In order to ensure a constant temperature throughout the sludge, it must be preheated to a temperature corresponding to the type of chosen fermentation. It is also necessary to daily recirculate a quantity of existent sludge with freshly preheated sludge.

From the analysis of the factors that determine the efficiency of the fermentation process, the main structural and technological requirements taken into account in the conception and design of the structure result and the following must be considered:

- the structural shape must be adapted to the hydraulic homogenizing and mixing spectrum and the equipment considered;
- structures must be thermal insulated to reduce heat losses and gas quantities necessary for sludge preheating. - besides the requirements for ensuring structural strength and stability, the fermentation tanks must ensure tightness to the sludge hydrostatic pressure and fermentation gases pressure.

- the requirement of durability of minimum 50 years requires the limitation of the crack opening in terms of tightness and especially due to the corrosive attack of the fermenting gas mixed with the water vapour. In order to avoid corrosive attack, it is necessary to provide anticorrosive protection inside, taking into account the acid-sulphurous type corrosion that occurs in the upper part of the tank.

- effort and deformation states must be determined taking into account both the actions modelled by force systems and the action of temperature variations taking into account sludge temperatures and maximum outdoor temperatures in the summer and winter season.

- depending on the storage capacity, it is necessary to consider the need to introduce the prestressing of concrete in order to eliminate the risk of cracking and increase the durability.

\section{Conception and design of the tanks structure}

Taking into account the wastewater flows and the concentration of the organic substance from the Nucet

\footnotetext{
* Corresponding author: cdtapusi@gmail.com
} 
farm, it resulted necessary to construct two fermentation tanks with the capacity of $1000 \mathrm{~m} 3$ each, as well as some annexes separated from the tanks by tightened permanent joints.

Considering the functional requirements, the capacity of a tank, the height of the sludge column and the values of the sectional efforts, the chosen reinforced concrete structural solution has the following components:

- a reinforced concrete circular matt foundation having the diameter of $17.50 \mathrm{~m}$ and a thickness of $40 \mathrm{~cm}$;

- a reinforced concrete cylindrical shell having a continuity connection with the foundation and an inner diameter of $16.00 \mathrm{~m}$, a height of $6.00 \mathrm{~m}$ and a thickness of $30 \mathrm{~cm}$;

- a plastic covering tightens to the concrete cylindrical shell walls and which, because of the gas pressure resulted in the fermentation process has a spherical shape;

- a floor of wood planks and beams, simply supported on the walls of the cylindrical shell and on a central interior structure sustained by a central column with the cross section $40 \times 40 \mathrm{~cm}$.

In order to ensure a favourable thermal balance, the tank was thermally insulated with expanded polystyrene applied on the cylindrical walls and extruded polystyrene under the tank foundation.

The foundation of the tanks was made on a ground with improved physical and mechanical characteristics at a depth of $2.50 \mathrm{~m}$.

The distance between the two tanks is $23.60 \mathrm{~m}$.

In the space between the reservoirs were made the annex constructions, in the form of reinforced concrete underground structures designated for installation and the equipment: pumping stations, preheating installations, equipment for crushing and shredding of materials.

\section{Hypothesis for determining the efforts and deformations in the structure}

Determining the state of stress and strain in the structure of a fermentation tank can be obtained by applying analytical computation or through numerical calculation methods using finite element method programs. Considering the structural system and the possibility of integrating the synthesis equations that define the state of effort in the structural elements (circular plates elastically supported and cylindrical shells), the analytical methods that allow expression of the interaction structure-stored fluid and foundation ground and define stresses and deformations through functions were chosen for computation. At the same time, there is the certainty of respecting equilibrium conditions and deformation compatibility in each structural element as well as on the boundaries of the joints between them.

\subsection{Loads and loads combination}

The considered fundamental load combination was taking into account: self-weights the hydrostatic pressure of the stored fluid, the pressure of the fermentation gases and the temperature variations.

The special load combination takes into consideration the hydrodynamic pressures induced by the seismic action also.

The design values of loads and their variation are shown in Figures 1, 2 and 3.

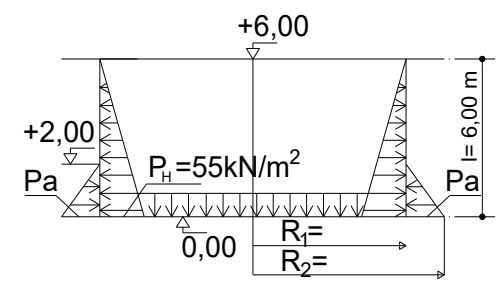

Fig. 1. Loads given by hydrostatic pressure gas pressure and active soil pressure.

where:

$p_{H}=$ the hydrostatic pressure; $55 \mathrm{kN} / \mathrm{m}^{2}$;

$p_{a}=$ the active soil pressure;

$p_{g}=$ the gas pressure; $2 \mathrm{kN} / \mathrm{m}^{2}$;

Following heat transfer calculations and taking into account a thickness of $12 \mathrm{~cm}$ thermal insulation at temperatures of:

$t_{i}=+45^{0} \mathrm{C}$ the temperature of the stored fluid;

$t_{e}=+35^{0} \mathrm{C}$ in the summer season;

$-25^{0} \mathrm{C}$ in the winter season;

the two temperature elementary fields acting on the structure are defined:

$$
\begin{gathered}
T_{0}=\frac{t_{i B}+t_{e B}}{2} \\
\Delta T_{0}=\frac{t_{i B}-t_{e B}}{2}
\end{gathered}
$$

Design values of the two fields considered stationary are shown in Figure 2.
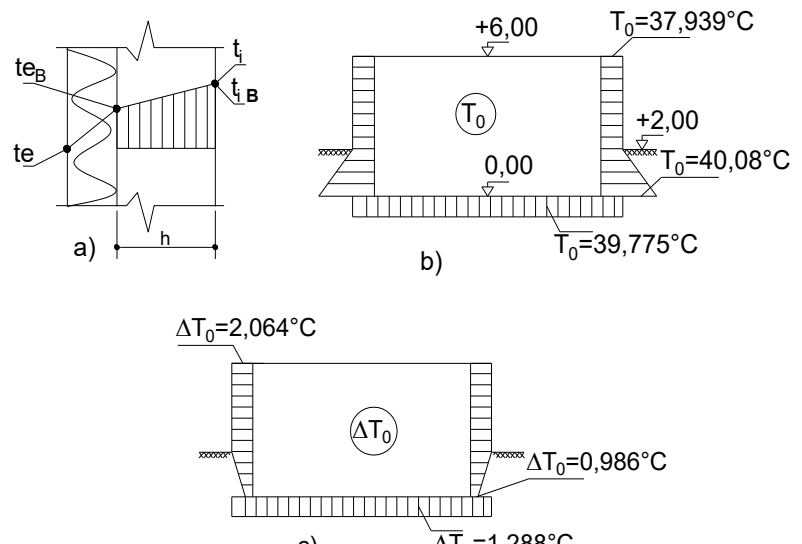

c) $\quad \overline{\Delta T}_{0}=1,288^{\circ} \mathrm{C}$

Fig. 2. Temperature variations. a) Temperature variation on element thickness; b) Variation of T0 field temperature during the winter season; c) Variation of the field temperature $\Delta \mathrm{T} 0$ in the winter season.

Variation of hydrodynamic pressures [1] and their design values are presented in Figure 3 and Table 1 respectively, for the seismic zone characterized by 
design ground acceleration $\mathrm{a}_{\mathrm{g}}=0.30 \mathrm{~g}$ and the corner period of the elastic response spectrum $\mathrm{T}_{\mathrm{c}}=1.0 \mathrm{~s}$.

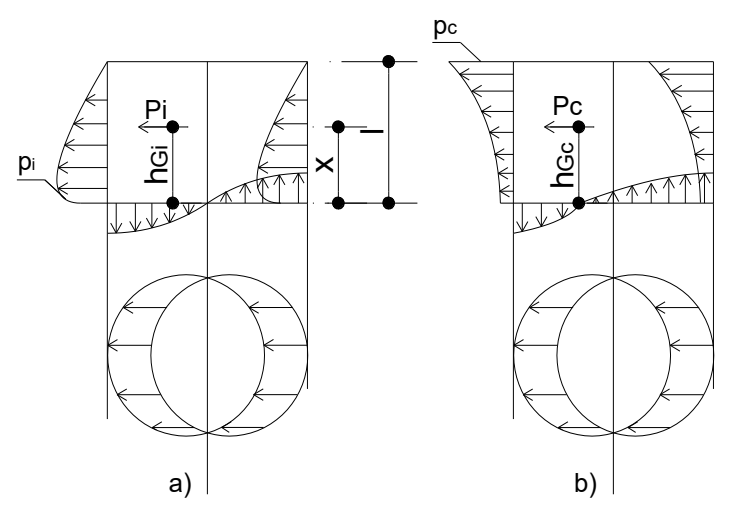

Fig. 3. Variation of hydrodynamic pressures induced by seismic action. a) Impulsive hydrodynamic pressures; b) Variation of convective hydrodynamic pressures.

Table 1. Impulsive, convective and total values of the hydrodynamic pressures.

\begin{tabular}{|c|c|c|c|}
\hline & $\begin{array}{c}\text { Impulsive } \\
\text { hydrodynamique } \\
\text { pressures } \\
{\left[\mathbf{k N} / \mathbf{m}^{2}\right]}\end{array}$ & $\begin{array}{c}\text { Conductive } \\
\text { hydrodynamiq } \\
\text { ue pressures } \\
{\left[\mathbf{k N} / \mathbf{m}^{2}\right]}\end{array}$ & $\begin{array}{c}\text { Total } \\
\text { pressures } \\
{\left[\mathbf{k N} / \mathbf{m}^{2}\right]}\end{array}$ \\
\hline 0.00 & 12.74 & 3.51 & 16.26 \\
\hline 0.10 & 12.65 & 3.55 & 16.21 \\
\hline 0.20 & 12.39 & 3.67 & 16.06 \\
\hline 0.30 & 11.95 & 3.87 & 15.82 \\
\hline 0.40 & 11.32 & 4.14 & 15.46 \\
\hline 0.50 & 10.47 & 4.52 & 14.99 \\
\hline 0.60 & 9.37 & 5.03 & 14.40 \\
\hline 0.70 & 7.97 & 5.70 & 13.67 \\
\hline 0.80 & 6.18 & 6.60 & 12.79 \\
\hline 0.90 & 3.82 & 7.93 & 11.76 \\
\hline 1.00 & 0.00 & 10.28 & 10.28 \\
\hline
\end{tabular}

The first three oscillation periods of sludge in the tank are: $\mathrm{T}_{1}=4,511 \mathrm{sec} ; \mathrm{T}_{2}=2.481 \mathrm{sec} ; \mathrm{T}_{3}=1.96 \mathrm{sec}$.

The results of hydrodynamic pressures and the global seismic moment at the face of the raft have the following values:

- results of impulse hydrodynamic pressures: $\mathrm{Pi}=$ $1214,36 \mathrm{kN}$;

- result of convective pressures: $\mathrm{Pc}=793,92 \mathrm{kN}$;

- total result: $\mathrm{Pi}+\mathrm{Pc}=2008,28 \mathrm{kN}$;

- global seismic moment: $\mathrm{Ms}=5200,54 \mathrm{kN}$;
We report the total result of hydrodynamic pressures to the stored sludge, resulting in a global seismic coefficient of $18.20 \%$.

$$
C_{s}=\frac{2008,28}{11053,10}=0,182
$$

\section{Analysis of the state of the efforts and deformations in the tanks structure}

Determining the stress and strain state for cylindrical tanks structure, composed by cylindrical shells and circular plates can be axially symmetric treated considering the axial symmetry of the structure and of the current loads: self-weights, hydrostatic pressures, temperature variations.

When comes to the action of hydrodynamic pressure induced by the occurrence of the seismic action, determining the stress and strain state of the structures must be non-symmetrically treated due to the antisymmetric nature of the hydrodynamic pressure.

The present paper presents the analytical design method used for determining axial symmetric state of stresses.

Admitting the linear elastic behaviour of the structure, the design algorithm implies the following design steps:

- breaking down the structure in component structural elements by suppressing their joints and replacing the suppressed connections with corresponding system of forces thus obtaining the basic system specific to the design method;

- analysis of the state of strain and deformation of the obtained cylindrical shells and circular plates subjected to bending.

Through this analysis the flexibility matrices for each structural element may be defined together with the membrane efforts for the cylindrical shell:

- expressing the deformation compatibility conditions along the connecting boundary and the alteration lines, a system of algebraic equations is obtained in which the unknowns are the boundary efforts, and the coefficients of the equations are the unit displacements and the displacements determined by loads;

- solving the equations system and finding the values of the sectional efforts along the joints boundaries;

- computing the final efforts applying the principle of superposition of effects.

Some main computation elements necessary for applying the previous explained algorithm are presented below.

\subsection{Breaking down the structure and building the basic system specific to the effort method}

Considering the structure lay-out and the variation of loads the obtained basic system is shown in Figure 4. 


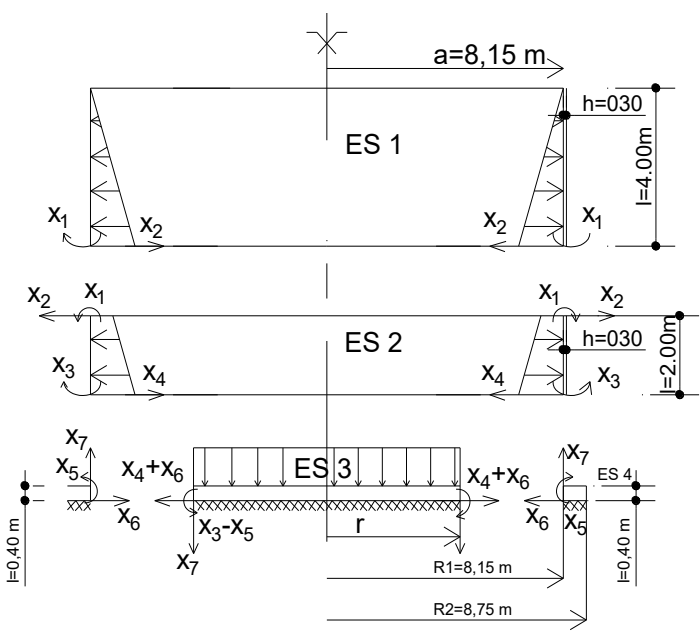

ES1 -

cylindrical shell, radius $\mathrm{a}=8,15 \mathrm{~m}$ height $\mathrm{l}=4,00 \mathrm{~m}$ and thickness $\mathrm{h}=0,30 \mathrm{~m}$.

ES2 - cylindrical shell, radius a $=8,15 \mathrm{~m}$ height $1=2,00$ $\mathrm{m}$ and thickness $\mathrm{h}=0,30 \mathrm{~m}$.

ES3 - circular flat plate supported on elastic foundation.

ES4 - circular hollow plate, supported on elastic foundation with:

$\mathrm{R} 1=8.5 \mathrm{~m} \mathrm{~h}=0.40 \mathrm{~m}$

$\mathrm{R} 2=8.75 \mathrm{~m}$.

$\mathrm{X}_{1}, \mathrm{X}_{2}, \mathrm{X}_{3}, \mathrm{X}_{4}, \mathrm{X}_{5}, \mathrm{X}_{6}, \mathrm{X}_{7}$ sectional stresses on the boundary.

Fig. 4. The basic system specific to the effort method when loading with the hydrostatic pressure.

\subsection{Defining the state of efforts and deformations for cylindrical shells}

According to the theory of cylindrical shells working in bending [5] [6] [2] the axial symmetric state of efforts and deformations is characterized by the sectional efforts shown in Figure 5 on an infinitesimal element.

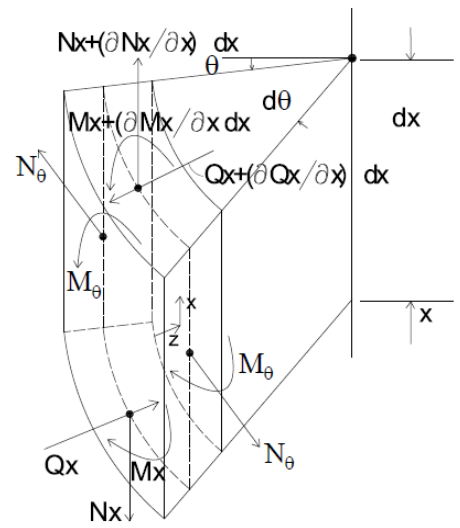

$\mathrm{N}_{\mathrm{x}}$ - axial stress along the cylinder generatrix direction

$\mathrm{N}_{\theta}$ - axial stress along a direction tangent to the circle

$\mathrm{Q}_{\mathrm{x}}$ - shear force

$\mathrm{M}_{\mathrm{x}}, \mathrm{M}_{\theta}$ - bending moments

$\mathrm{X}_{(\mathrm{x})}$ - surface loads component along the generatrix direction

$\mathrm{Z}_{(\mathrm{x})}$ - surface loads component normal to the surface

Fig. 5. Positive sectional efforts considered on a cylindrical shell infinitesimal elements.
The synthesis differential equation of the bending theory is obtained from the following general equations: equations of equilibrium, equivalence relationships, deformation equations, physics equations, choosing as basis unknown the displacement function $\mathrm{w}_{(\mathrm{x})}$ in the direction of the normal to the median surface of the curved plate.

Considering the case of axial symmetrical loads and taking into account the force systems and the two elementary temperature fields $\mathrm{T}_{0(\mathrm{x})}$ and $\Delta \mathrm{T}_{0}(\mathrm{x})$, acting on the curved plate, the synthesis equation has the following form:

$$
\begin{aligned}
& \frac{d^{4} w}{d x^{4}}+4 k^{4} w=-\frac{z_{(x)}}{B}-\frac{\mu}{B a}\left(C-\int X_{(x)} d x\right)+ \\
& 4 k^{4} a \alpha_{t} T_{0(x)}+2(1+\mu) \frac{\alpha t}{h} \cdot \frac{d^{2} \Delta T_{0(x)}}{d x^{2}}
\end{aligned}
$$

Performing in (4.1) the change of the variable $\xi=\mathrm{x} / \mathrm{l}$ and denoting the product $\mathrm{K} \times 1=\lambda$ the equation of synthesis becomes:

$$
\begin{aligned}
& \frac{d^{4} w}{d x^{4}}+4 \lambda^{4} w=-\frac{z_{(\xi)} l^{4}}{B}-\frac{\mu l^{4}}{B a}\left(C-\int X_{(\xi)} d \xi\right)+ \\
& 4 \lambda^{4} a \alpha_{t} T_{(\xi)}+2(1+\mu) l^{2} \frac{\alpha t}{h} \cdot \frac{d^{2} \Delta T_{0(\xi)}}{d \xi^{2}}
\end{aligned}
$$

The general solution of the synthesis equation consists of the solution of the homogeneous equation $W_{0(\xi)}$ plus a particular solution depending on the loading functions type on the right hand side of the equation.

$$
\begin{gathered}
W_{(\xi)}=W_{0(\xi)}+W_{p(\xi)} \\
W_{(\xi)}=W_{p(\xi)}+C_{1} \operatorname{ch}(\lambda \xi) \cos (\lambda \xi)+C_{2} \operatorname{ch}(\lambda \xi) \sin (\lambda \xi)
\end{gathered}
$$

In equations (4), (5), (6) and (7) the following notations were used:

$W_{(\xi)}=$ displacement function of a point on the median surface along a direction normal to it;

$$
k=\frac{\sqrt[4]{\partial\left(1-\mu^{2}\right)}}{\sqrt{a h}}=\text { damping factor of the cylindrical }
$$

shell;

$B=\frac{E h^{3}}{12\left(1-\mu^{2}\right)}=$ bending stiffness of cylindrical shell;

$\xi=\frac{x}{l}=$ non-dimensional co-ordinate;

$\alpha_{t}=$ thermal dilatation coefficient;

$\mu=$ Poisson's coefficient.

Knowing the general solution of the synthesis equation, sectional efforts can be calculated with the relationships: 


$$
\begin{aligned}
& N_{x}=-l \int X_{(\xi)} d \xi+C \\
& N_{x}=D\left[\left(\frac{1}{l} \cdot \frac{d u}{d \xi}+\mu \cdot \frac{w}{a}\right)-(1+\mu) \alpha_{t} T_{0(\xi)}\right] \\
& N_{\theta}=D\left[\left(\frac{w}{a}+\frac{\mu}{l} \cdot \frac{d u}{d \xi}\right)-(1+\mu) \alpha_{t} T_{0(\xi)}\right] \\
& M_{x}=\frac{B}{l^{2}}\left[\frac{d^{2} w}{d \xi^{2}}-2(1+\mu) \frac{\alpha_{t}}{h} l^{2} \Delta T_{0(\xi)}\right] \\
& M_{\theta}=\frac{B}{l^{2}}\left[\mu \frac{d^{2} w}{d \xi^{2}}-2(1+\mu) \frac{\alpha_{t}}{h} l^{2} \Delta T_{0(\xi)}\right] \\
& Q_{x}=\frac{B}{l^{3}}\left[\frac{d^{3} w}{d \xi^{3}}-2(1+\mu) \frac{\alpha_{t}}{h} l^{2} \frac{d \Delta T_{0(\xi)}}{d \xi}\right]
\end{aligned}
$$

where:

$d=\frac{E h}{1-\mu^{2}}=$ axial stiffness of the cylindrical shell;

$B=\frac{E h^{3}}{12\left(1-\mu^{2}\right)}=$ bending stiffness of the cylindrical shell;

$X=\frac{d w}{d x}=\frac{1}{l} \cdot \frac{d w}{d \xi}=$ rotation of the cylindrical shell generatrix;

$E=$ the material modul of elasticity.

Integration constants $\mathrm{C}_{1}, \mathrm{C}_{2}, \mathrm{C}_{3}, \mathrm{C}_{4}$ are determined by expressing the boundary conditions for each supporting case and /or load.

In the case of cylindrical shells, the particular solution $\mathrm{W}_{\mathrm{p}(\xi)}$ coincides with the membrane solution, which allows the superposition of the strains and deformations of the membrane with the strains and deformations given by the boundary forces.

\subsection{Defining the state of stresses and strains in the circular plates supported on elastic foundations}

The state of axial symmetric efforts and deformations in circular plates for the general case of loading - systems of forces acting in the plan or normal to the plan of the circular plates plus the two elementary temperature variations - is characterized by the sectional efforts shown in Figure 6.

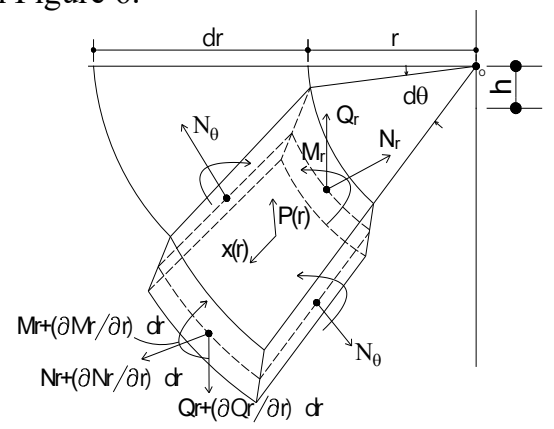

Fig. 6. Positive sectional stresses in the axial symmetrical case.
The state of efforts in the circular plates when loaded with a system of forces acting in its plan together with the elementary component $\mathrm{T}_{0}(\mathrm{x})$ of the temperature variation can be studied as a plane problem, the expressions of the efforts and the deformations of interest for the present work are presented in the following tables [3]:

Table 2. Formatting sections, subsections and subsubsections.

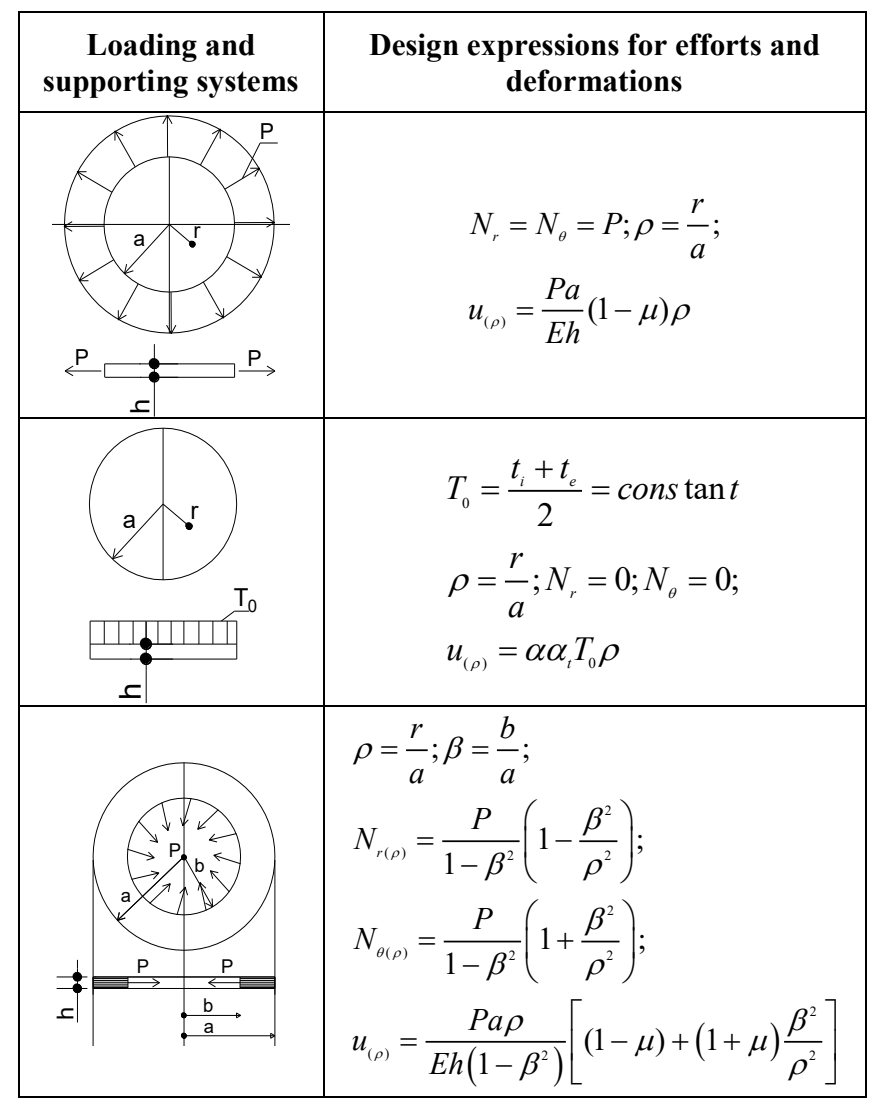

The subject of circular plates on elastic foundations working in bending when loaded with a system of forces acting in its plan together with the elementary component $\mathrm{T}_{0(\mathrm{x})}$ of the temperature variation can be studied using several models for the soil-element interaction.

Using the Winkler model and defining as elastic characteristic the bed coefficient $\left(\mathrm{C}_{\mathrm{EO}}\right)$ the synthesis equation of the circular plates working in bending and supported on elastic foundation is: [3][4].

$$
\begin{aligned}
& L_{\alpha}\left[L_{\alpha}\left(w_{(\alpha)}\right)\right]+w_{(\alpha)}=\frac{p_{(\alpha)} \alpha^{4}}{B \lambda^{4}}-2(1+\mu) \cdot\left(\frac{\alpha}{\lambda}\right) . \\
& \cdot 2 \cdot \frac{\alpha_{t}}{h} \cdot\left(\frac{d^{2} \Delta T}{d \alpha^{2}}+\frac{1}{\alpha} \cdot \frac{d \Delta T}{d \alpha}\right)
\end{aligned}
$$

In the synthesis equation 4.6 the following notations were used:

$$
\begin{aligned}
\rho & =\frac{r}{a} \\
\alpha & =\rho \lambda
\end{aligned}
$$


$\lambda=a^{4} \sqrt{\frac{c_{0}}{B}}=$ flexibility index of the plate;

$B=\frac{E h^{3}}{12\left(1-\mu^{2}\right)}=$ bending stiffness of the plate;

$L_{\alpha}=\frac{d^{2}()}{d \alpha^{2}}+\frac{1}{l} \cdot \frac{d()}{d \alpha}=$ differential operator;

$r=$ radius in a point;

$a=$ the outer radius of the plate;

$\alpha_{t}=$ the coefficient of expansion of the material;

$\Delta T(\alpha)=\frac{t_{i}-t_{e}}{2}=$ the elementary component of the thermal field varying linearly along thickness;

$E=$ elastic modulus of the material;

$\mu=$ Poisson's coefficient.

The general solution of the synthesis equation composed of a particular solution and the solution of the homogeneous equation can be expressed with the help of Bessel functions in the form: [3]

$$
\begin{aligned}
& w_{(\alpha)}=w_{p(\alpha)}+C_{1} \operatorname{ber}(\alpha)+C_{2} \operatorname{bei}(\alpha)+C_{3} \operatorname{ker}(\alpha)+ \\
& +C_{4} \operatorname{kei}(\alpha)
\end{aligned}
$$

Knowing the general solution in (4.7) the expressions of sectional efforts are:

- Rotation:

$$
\chi=-\frac{\lambda}{a}\left[\begin{array}{l}
\frac{d w_{p}}{d \alpha}+C_{1} b e r^{\prime}(\alpha)+C_{2} \operatorname{ber}^{\prime}(\alpha)+ \\
+C_{3} \operatorname{ker}(\alpha)+C_{4} \operatorname{kei}(\alpha)
\end{array}\right]
$$

- Expressions of sectional efforts:

$$
M_{r(\alpha)}=-B \frac{\lambda^{2}}{a^{2}}\left[\begin{array}{l}
\left(\frac{d^{2} w_{p}}{d a^{2}}+\frac{\mu}{\alpha} \cdot \frac{d w_{p}}{d \alpha}\right)-C_{1}(C)+ \\
+\left(\frac{1-\mu}{\alpha} \operatorname{ber}^{\prime}(\alpha)\right)+ \\
-C_{2}\left(\operatorname{ker}(\alpha)-\frac{1-\mu}{\alpha} b e i^{\prime}(\alpha)\right)- \\
+C_{4}\left(\operatorname{ker}(\alpha)-\frac{1-\mu}{\alpha} \operatorname{ker}^{\prime}(\alpha)\right)+ \\
+2(1+\mu) \frac{a^{2}}{\lambda^{2}} \cdot \frac{\alpha_{t}}{h} \Delta T_{(\alpha)}
\end{array}\right](
$$

$$
\begin{aligned}
& {\left[\left(\frac{1}{2} \cdot \frac{d w_{p}}{d \alpha}+\mu \frac{d^{2} w_{p}}{d \alpha^{2}}\right)-\right.} \\
& -C_{1}\left(\mu b e i(\alpha)-\frac{1-\mu}{\alpha} \operatorname{ker}^{\prime}(\alpha)\right)+ \\
& M_{\theta}=-B \frac{\lambda^{2}}{a^{2}} \mid \begin{array}{l}
+C_{2}\left(\mu b e r(\alpha)-\frac{1-\mu}{\alpha} \operatorname{bei}^{\prime}(\alpha)\right)- \\
-C_{3}\left(\mu k e i(\alpha)-\frac{1-\mu}{\alpha} \operatorname{ker}^{\prime}(\alpha)\right)+
\end{array} \\
& +C_{4}\left(\mu k e r(\alpha)+\frac{1-\mu}{\alpha} k e i(\alpha)\right)+ \\
& +2(1+\mu) \frac{a^{2}}{\lambda^{2}} \cdot \frac{\alpha_{t}}{h} \Delta T_{(\alpha)} \\
& Q_{r(\alpha)}=-B \frac{\lambda^{3}}{a^{3}}\left[\begin{array}{l}
\left(\frac{d^{3} w_{p}}{d \alpha^{3}}+\frac{1}{\alpha} \cdot \frac{d^{2} w_{p}}{d \alpha^{2}}-\frac{1}{\alpha^{2}} \cdot \frac{d w_{p}}{d \alpha}\right)- \\
-C_{1} b e i^{\prime}(\alpha)++C_{2} \text { ber }(\alpha)- \\
-C_{3} k e i^{\prime}(\alpha)+C_{4} \operatorname{ker}^{\prime}(\alpha)
\end{array}\right]
\end{aligned}
$$

In relationships (10), (11), (12), (13) it was noted:

$$
\frac{d}{d \alpha}()=()^{\prime}
$$

ber $\alpha$, bei $\alpha$, ker $\alpha$, kei $\alpha$ Thompson - Kelvin functions

The integration constants are determined by expressing the boundary conditions for each specific loading and supporting case. In the case of solid circular plates (not hollowed) constants $\mathrm{C}_{3}$ and $\mathrm{C}_{4}$ are null if the displacement $\mathrm{w}_{(\alpha)}$ is finite in the centre of the slab.

Based on the previously presented algorithms together with the specified analytical relationships for each structural element and using a computation software, a design routine has been processed allowing the determination of efforts and deformations values for the entire structure considering the soil-structure interaction also.

The physical-mechanical characteristics considered were:

- concrete class $\mathrm{C} 20 / 25$;

- the concrete modulus of elasticity $\mathrm{E}_{\mathrm{b}}=$ $300.000 \mathrm{daN} / \mathrm{cm}^{2}$

- the Poisson coefficient of concrete $\mu=0.20$;

- bed coefficient of the foundation soil, $\mathrm{C}_{\mathrm{E} o}=$ $15.000 \mathrm{kN} / \mathrm{m}^{3}$.

The results obtained with for the values of the sectional efforts and their variation and are presented in the diagrams in Figures 7 and 8. 


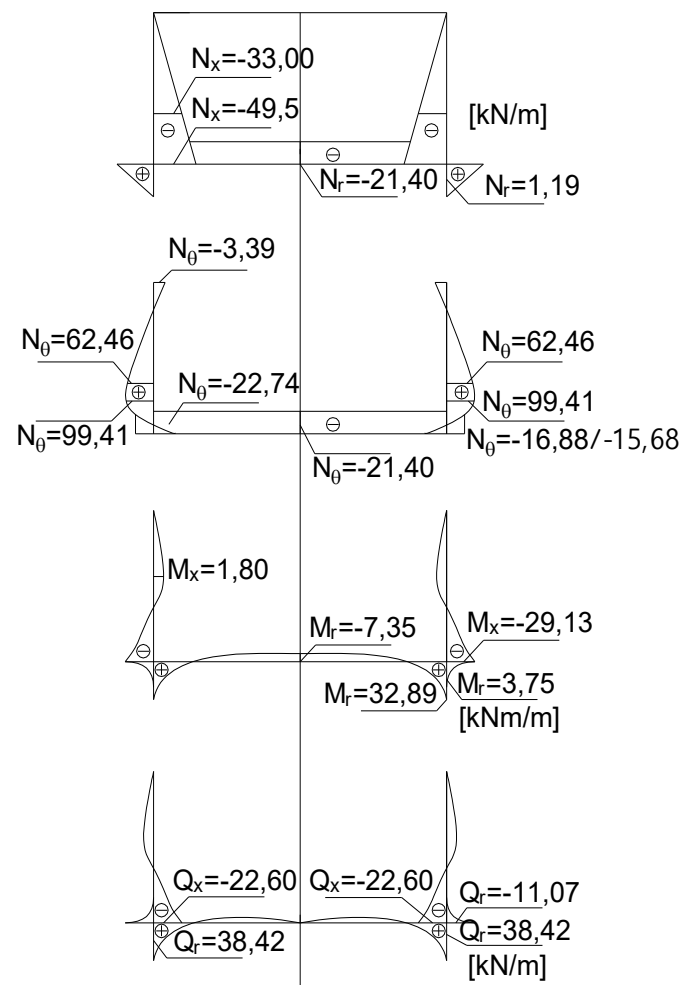

Fig. 7. Sectional efforts diagram when loading with the selfweight.

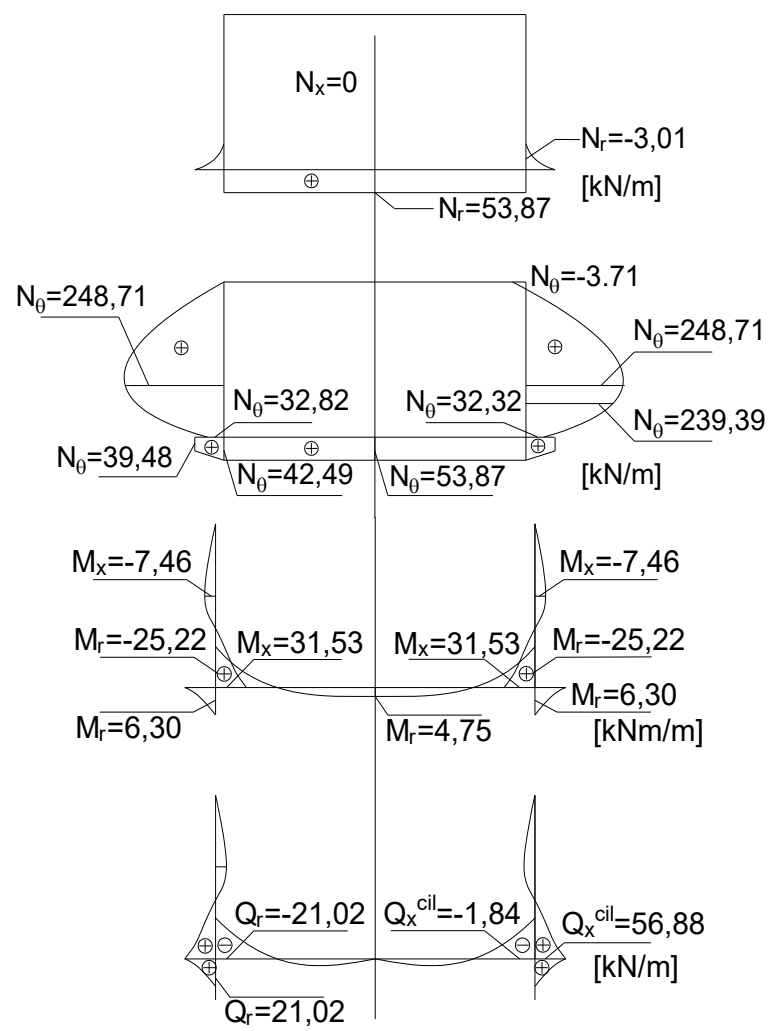

Fig. 8. Sectional efforts diagram due to hydrostatic pressure action.

\section{Conclusions}

The work presented in this article was issued in the design process of the two Nucet farm digester structures, having a capacity of $1000 \mathrm{~cm}^{3}$ each. The fermentation tanks are in function already, proving a good structural and functional behavior.

It was proven that for axial-symmetric loads like selfweights, hydrostatic pressures, gas pressure or soil active pressure, the design analytical method presented in this paper may be used, existing the certainty of respecting the forces equilibrium conditions and deformations compatibility for the entire structure.

If the anti-symmetric loads like hydrodynamic pressure are taken into consideration, the use of presented analytical method becomes more complicated as the synthesis equation is more complex (is an 8-th order partial derivative equation).

It is concluded also that, as the reinforced concrete tanks are acted by temperature variations also, the stiffness of the cylindrical shells must be expressed corresponding to a cracked state, otherwise it exists the danger of over evaluating temperature loads.

Following the design procedure, it also resulted the fact that if larger digesters are needed having capacities over $1000 \mathrm{~cm}^{3}$, a prestressed reinforced concrete solution it is advisable to be used rather than the solutions used for the design presented in this paper.

\section{References}

1. D. Furis, Calculul si conceptia structurilor axial simetrice aplicate in tehnica tratarii si epurarii apei, luand in considerare rezemarea lor pe mediul elastic, Teza de doctorat, Bucuresti (1979)

2. D. Cretu, Teoria elasticitatii, Ed. Conspress, Bucuresti (2004)

3. D. Furis, R. Erbasu, M. Sandru, B. Butnaru, Stari de eforturi si deformatii in placi circulare, Ed. Conspress, Bucuresti (2016)

4. D. Furis, R. Erbasu, L. Sorohan, Analiza interactiunii structurilor cu terenul de fundare in domeniul elastic, Ed. Conspress, Bucuresti (2017)

5. E. Hampe, Statik Rotationssymetricher flachentragewerke, pag.966-1003, Ed. Tehnica, Bucuresti (1986)

6. S.P. Timoshenko, S. Woinowsky-Krieger, Teoria placilor plane si curbe - traducere din limba engleza Editura Tehnica, Bucuresti (1970)

7. *** CR0/2012 Cod de proiectare. Bazele proiectarii constructiilor 